\title{
Editorials
}

\section{Is UK general practice education and training now fit for purpose?}

\section{INCREASING JOB DEMANDS FOR GPS}

Recent major structural and policy developments in the UK health services have significantly impacted on the primary role of the GP as a generalist clinician; there is increasing emphasis on their capabilities as team leaders, care coordinators, educators, and commissioners. ${ }^{1}$ Sir Bruce Keogh, the NHS Medical Director in England, is exploring issues of demand for services and the need to ensure people with longterm conditions are better looked after outside the hospital system, thus reducing their need for emergency care services. The Health Secretary for England, Jeremy Hunt, is calling for better integration between the health and social care systems, which implies a significantly revised model for the delivery of primary care. NHS England launched "Call to Action"2 to stimulate debate in communities and enable GPs to play a stronger role in delivery of out-ofhospital integrated services for an improved patient experience, personalised care, with more effective and efficient use of the resources. In the devolved administrations there are similar policy directives reflecting the wish to increase care in the community in the future. ${ }^{3-5}$ Consequently, there are significantly increasing job demands, not least from patients, for GPs to be better prepared to manage increasingly complex long-term conditions. To what extent do the current curriculum, the training provision, and the licensure assessments accommodate these changes?

\section{EVIDENCE FOR NEW COMPETENCIES REQUIRED IN A BROADER GP JOB ROLE}

New evidence from a multi-source, multimethod job analysis study ${ }^{6}$ (involving interviews, focus groups, observations of GPs at work, a survey; $n=>1400$ ) identifies a framework of eleven competency domains including:

- Empathy and perspective-taking

- Communications skills

- Clinical expertise

- Conceptual thinking and problem-solving

- Organisation and management of resources

- Professional integrity

- Coping with pressure

- Effective teamworking
- Respect for diversity and the law

- Learning and development of self and others

- Leading for continuing improvement.

GPs are required to consider how their work impacts on communities: both to address the health of the population they serve, and how this is managed within the wider health service, with new competencies now required (such as Leading for continuing improvement) compared to an original job analysis conducted over 10 years ago?

Research evidence is sparse regarding the skills and attributes required by community generalists to be effective as their role expands outside of the consulting room, especially relating to planning services for population-based healthcare and proactive preventative care for those at risk. ${ }^{6}$

\section{IMPLICATIONS FOR WORK DESIGN AND TRAINING VALIDITY}

Research evidence highlights three core themes arising that have significant implications for work design in general practice, including increased role breadth, increased potential for role conflict, and concerns around the level of preparedness for practice after training. ${ }^{6}$

Regarding an increased role breadth, results show an enhanced emphasis for GPs to consider multiple agendas beyond the patient and their practice in future. GPs are required to focus on balancing individual (local) needs versus their registered population's health (such as 'bigger-picture' thinking), and to take on multiple complex roles in future. However, there is increased potential for conflict in relation to ethical values. GPs are required to demonstrate commitment to patient care and maintain patient trust, which may at times conflict with managing limited resources. Increasingly, GPs need to resolve these significant competing tensions to be effective in their role. For individuals, there is a potential ethical conflict between these tensions, which may be at odds with their identity as a clinician. Research in work design implies this will increase the risks of experiencing workrelated stress, reduced job satisfaction, and burnout. ${ }^{8}$ With competing job demands for individuals, to remain effective, trainees will require specific support to deal with these conflicts and significant changes in work design.

There are identified concerns regarding the level of trainee preparedness for practice given these new job demands. For example, there are gaps in training provision relating to dealing with challenging psychosocial issues and complex long-term health conditions facing patients. Several new domains relate to an increasingly broad range of non-clinical activities such as leading for innovation, business acumen, adopting collaborative approaches when working in expanded multiprofessional teams ${ }^{6}$ (in addition to managing healthcare pathways effectively). which are not currently assessed in training or tested directly by the current MRCGP licensure exams.

To what extent do trainees feel confident that they are able to carry out a broader and more proactive role? Self-efficacy is an important motivational dimension to consider in future education and training activities as it influences individual goals, emotional reactions, effort, coping, and wellbeing.

This proposition is consistent with survey data from recently qualified GPs now reporting significantly higher levels of stress than their counterparts, ${ }^{9}$ and with evidence showing a significantly increased number of GPs intending to quit. ${ }^{10}$ There

\section{"Research highlights significant implications for work design including increased role breadth, increased potential for role conflict, and concerns around the level of preparedness for practice after training.}




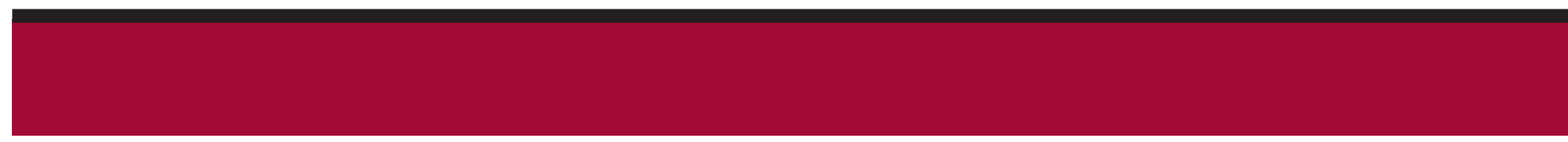

\section{"By ensuring that the education and training provided is fit for purpose, newly-qualified GPs will be fit for practice, in an increasingly challenging workplace.}

is also a risk that perceived stress in the profession will affect recruitment in future; at a time when the number of GPs needs to expand.

\section{THE CASE FOR TRAINING TO BE RECONFIGURED?}

Given the extensive range of responsibilities and capabilities required, this work supports the case for enhancement of the current training provision to ensure it reflects the role changes and the greater breadth of competencies now needed by GPs. To ensure validity, further work is required to define the optimal content and construction of training to support the career pathway land, by extension, patient care) appropriately in future.

The educational value of reconfiguring GP training by the RCGP to encompass these and other new domains has been widely recognised by health departments. Inevitably, there will be differences in the role of GPs in the health systems across the UK, but it is essential that there is a single set of national training standards that are fit for purpose.

Much of the training should now take place in posts that provide services in community settings, with a focus on GPs leading the response to population health issues, developing generalist competencies and working collaboratively in multiprofessional teams to develop expertise together to tackle the increasing complex profile of patients with long-term conditions. Such posts should play a key role in facilitating the shift of patient care into the community, supporting new models of emergency care, and contributing to the development of in- and out-of-hours services. ${ }^{11}$ Flexibility in the nature of these posts at a local level is important to ensure the provision of the highest quality training environments, and provide for a cost-effective method of delivery. All programmes will need to follow a well-defined curriculum setting out new competencies that can be acquired in a wide variety of training environments; service delivery should be an important component, as will working in multiprofessional teams, supported by high quality mentoring and support systems for future GP trainees.

Given that the first cohort of trainees recruited into new educationally approved extended programmes are unlikely to reach the start of their fourth year until 2018, there is time to plan the essential changes in service delivery and to revise aspects of the curriculum, while also providing the new community-based training posts in a cost-effective manner. The result will be a better trained, confident, and capable GP workforce, educated in an environment that delivers new models of high quality patient care. By ensuring that the education and training provided is fit for purpose, newlyqualified GPs will be fit for practice, in an increasingly challenging workplace.

\section{Fiona Patterson,}

Principal Researcher, University of Cambridge and Director of Work Psychology Group, Cambridge.

\section{Amanda Howe,}

Honorary Secretary of Council, Royal College of General Practitioners, London.

\section{Abdol Tavabie,}

GP Dean for Health Education, Kent, Surrey and Sussex.

\section{Mike Watson OBE,}

Former Medical Director, NHS Education Scotland.

\section{Provenance}

Commissioned; not externally peer reviewed.

DOI: 10.3399/bjgp13X674305

\section{ADDRESS FOR CORRESPONDENCE}

Fiona Patterson

Department of Psychology, University of

Cambridge, Downing Street, Cambridge, CB2 3EB

E-mail: F.pattersonaworkpsychologygroup.com E-mail: fcp27acam.ac.uk

\section{REFERENCES}

1. Department of Health. Equity and excellence: liberating the NHS. London: DOH, 2010.

2. NHS England 2013. Improving general practice - a call to action http://www. england.nhs.uk/ourwork/com-dev/igp-cta/ laccessed 9 Oct 2013).

3. The Scottish Government. Better Health Better Care: Action Plan. http://www.scotland. gov.uk/Publications/2007/12/11103453/0 laccessed 9 Oct 2013).

4. Department of Health, Social Services and Public Safety. Transforming Your Care; Vision to Action. NI Health and Social Care Board, 2013. http://www.dhsspsni.gov.uk/tyc.htm laccessed 9 Oct 2013).

5. Welsh Government. Together for Health: A five year vision of the NHS in Wales. 2012. http://wales.gov.uk/topics/health/ publications/health/reports/together/ laccessed 9 Oct 2013).

6. Patterson F. Tavabie A, Denney M, et al. A new competency model for general practice Implications for selection, training, and careers. Br J Gen Pract 2013; DOI: 10.3399/ bjgp13X667196.

7. Patterson F, Ferguson $E$, Lane $P$, et al. $A$ competency model for general practice: Implications for selection and development. Br J Gen Pract 2000; 50(452):188-193.

8. Jackson SE, Schuler RS. A meta-analysis and conceptual critique of research on role ambiguity and role conflict in work settings. Organisational Behaviour and Human Decision Processes 1985; 36: 16-78.

9. BMA. Health Policy and Economic Research Unit. Seventh report. Cohort Study 2006 medical graduates. London, BMA, 2013.

10. Hann M, McDonald J, Checkland K, et al. Department of Health Policy Research Programme, August 2013. Seventh National GP Worklife Survey. http:// wuw.population-health.manchester ac.uk/healtheconomics/research/ FinalReportofthe7thNationalGPWorklifeSurvey. pdf (accessed 9 Oct 2013).

11. Thorlby R. Reclaiming a population health perspective: Future challenges for primary care. http://uww.nuffieldtrust.org.uk/ publications/reclaiming-population-healthperspective (accessed 9 Oct 2013). 